\title{
PEMANFAATAN YOUTUBE SEBAGAI SARANA TRANSFORMASI MAJALAH HIGHEND
}

\author{
${ }^{1}$ Yolanda Stellarosa \\ ${ }^{2}$ Sandra Jasmine Firyal \\ ${ }^{3}$ Andre Ikhsano \\ 1,2,3 Program Studi Ilmu Komunikasi, Sekolah Tinggi Ilmu Komunikasi, London School of Public Relations Jakarta \\ Email: ${ }^{1}$ yolanda.s@1spr.edu
}

\section{ARTICLE INFO}

\author{
ABSTRACT
}

Keywords:

Social Media, Magazine,

Youtube, Highend,

Transformation
The emergence of a variety of social media makes it easier for people to find and obtain information. One of the social media that can provide information in the form of audio and visual without any duration limit is YouTube.YouTube HighEnd Magazine is HighEnd magazine's YouTube channel used as a transformation tool for the magazine. This research uses descriptive qualitative method. The purpose of this study is to determine the utilization of social media YouTube as a tool of transformation of HighEnd magazine. Researcher interviewed three different speakers that have different job desks, Larasati Oetomo as digital media officer, Lysia Jessica as editor in chief, and Johan Jang as social media expert. This research uses new media theory and describes media utilization strategies to find out how Highend magazine utilizes YouTube's social media. This research proves that HighEnd has utilized YouTube social media with six characteristics of New Media as a means of transformation of print media, has also developed strategies in utilizing YouTube based on Audience, Mission, Goal, and Content Strategy.

\section{PENDAHULUAN}

Perkembangan teknologi semakin mempermudah manusia untuk mengakses informasi melalui internet. Adanya internet pun mengakibatkan hadirnya begitu banyak media sosial, seperti facebook, twitter, instagram, YouTube dan lain sebagainya, yang dijadikan wadah bagi manusia untuk saling berkomunikasi atau bersosialisasi, bertukar informasi, mempertemukan teman lama maupun baru, ataupun menunjukan eksistensi diri mereka. Informasi yang ditampilkan dalam bentuk audio visual semakin menambah daya tarik penggunaan sosial media. Kemudahan menggunakan media sosial membuat media sosial itu sendiri sangat diminati oleh khalayak saat ini sebagai sarana untuk mendapatkan informasi.

YouTube sebagai salah satu media sosial adalah sebuah situs web video sharing (berbagi video) yang populer dimana para pengguna dapat memuat, menonton, dan berbagi klip video secara gratis. YouTube didirikan pada bulan Februari 2005 oleh tiga orang mantan karyawan PayPal, yaitu Chad Hurley, Steve Chen dan Jawed Karim. Umumnya video-video di YouTube adalah video klip film, TV, serta video buatan para penggunanya sendiri (Faiqah, Nadjib, \& Amir, 2016:259). Menurut Press@google.com (dalam YouTube Untuk Pers, n.d.) bahwa YouTube memiliki lebih dari satu miliar pengguna, hampir sepertiga dari semua pengguna internet, dan setiap hari pengguna tersebut menonton miliaran jam video dan menghasilkan miliaran kali penanyangan. Di perangkat seluler, YouTube telah menjangkau lebih banyak penonton yang berusia 18-34 tahun dan 18-49 tahun daripada jaringan telivisi kabel manapun di Amerika Serikat. YouTube diterjemahkan lebih di 88 negara dan dapat diakses dalam 76 bahasa (yang mencangkup 95\% dari populasi internet). Menurut data yang dirilis We are Social Singapore, media sosial yang paling sering digunakan di Indonesia adalah YouTube dengan persentase 49\% (Slideshare.net, 2017, Januari 26). YouTube merupakan salah satu media yang berkembang saat ini, diminati oleh khalayak karena pada YouTube setiap orang dapat mengunggah video secara gratis dan dengan durasi yang tidak ada batasnya. Media sosial ini dari segi informasi membuat khalayak mendapatkan banyak informasi yang ada di dalamnya.

Tidak hanya pada internet, perubahan juga terjadi pada media cetak, salah satunya pada majalah. Di era teknologi saat ini, majalah tidak bisa hanya fokus pada model cetak, akan tetapi harus 
mengikuti perkembangan zaman untuk dapat terus bertahan. Hal ini terjadi pada majalah first-class lifestyle HighEnd. Dalam menghadapi banyak pesaing di industri majalah, diperlukan strategi tertentu yang dilakukan oleh majalah HighEnd, salah satunya dengan memanfaatkan media sosial YouTube sebagai sarana transformasi majalah mereka.

HighEnd merupakan majalah yang berasal dari Indonesia, diterbitkan pertama kali pada tahun 2008 dalam Bahasa Inggris oleh PT MNI Entertainment. Majalah HighEnd merupakan majalah yang memperlihatkan gaya hidup kelas satu, ditujukan untuk pembacanya yang terdiri dari kaum elite, sosialita, ekspatriat, hingga pengusaha. Konsistensi HighEnd dalam memberikan yang terbaik dari dunia fashion, beauty, traveling, men's muse adalah yang membuat majalah ini bertahan sampai sekarang. Majalah HighEnd memiliki target market A dengan target pembaca antara lain pengusaha, sosialita Indonesia, pekerja dengan profesi yang eksklusif dan setaranya dengan jangkauan umur 3545 tahun (HighEnd, 2017). Kompetitor dari majalah HighEnd seperti BAZAAR, PRESTIGE, dan Dewi. Majalah HighEnd menggunakan beberapa media sosial dalam memperkenalkan majalah tersebut, di antaranya: pertama adalah facebook dimana memiliki followers sebanyak 1.208 dengan total likes 1.219. Namun penggunaan facebook telah terhenti sejak 2012. Kedua adalah twitter (@highendofficial), memiliki followers sebanyak 2.335 dan bergabung di media sosial twitter pada Desember 2014. Ketiga adalah instagram (@highendmagazine), memiliki followers sebanyak 7.407 pertanggal 1 Oktober 2017. Yang terakhir adalah YouTube (HighEnd Magazine), dimana telah disubscribe sebanyak 445 berdasarkan data per tanggal 1 Oktober 2017. HighEnd Magazine telah bergabung di media sosial YouTube sejak Mei 2011.

Penelitian ini fokus pada YouTube walaupun terdapat empat media sosial yang digunakan sebagai media komunikasi dan informasi majalah HighEnd. Hal ini disebabkan karena YouTube HighEnd Magazine merupakan media sosial yang mampu menyebarkan informasi yang dikemas dalam bentuk video dengan durasi yang lebih lama dibandingkan dari ketiga media sosial lainnya yang dimiliki majalah HighEnd.

Perbedaan tampilan antara majalah dengan YouTube terlihat cukup berbeda. Dimana di dalam majalah, pembaca hanya dapat melihat satu foto monoton dan membaca artikel yang cukup panjang. Sedangkan di YouTube, pembaca dapat melihat foto monoton tersebut bergerak, menjawab pertanyaan-pertanyaan yang dilontarkan, dan pembaca bisa dengan leluasa mendengarkan sambil melihat isi video tersebut.

Melihat peluang yang ada, perubahan dilakukan oleh majalah HighEnd yang selama ini menerbitkan versi cetak, kemudian membuat versi onlinenya melalui akun YouTube dengan salah satu tujuannya yaitu menyasar pembaca baru di usia belasan sampai 30 tahun. Hal ini didukung dengan data yang dirilis oleh We are Social pada Januari 2017, tertera bahwa media sosial yang paling aktif digunakan di Indonesia adalah YouTube dengan persentase 49\%. Data tersebut diambil berdasarkan usia antara 16-64 tahun. Menurut survey Pew Internet (dalam Maheswara \& Dwiutami, 2013:52) sebanyak 75\% dewasa muda berusia 18-24 tahun memiliki akun jejaring sosial. Usia dewasa muda memiliki dorongan untuk merasa terhubung dengan orang lain yakni dalam membina hubungan hangat, dekat, dan komunikatif. Penggunaan jejaring sosial penting bagi seseorang dewasa muda untuk memenuhi kebutuhan individual dan interpersonalnya.

YouTube HighEnd Magazine adalah media sosial yang memberikan informasi seputar fashion lifestyle. Informasi tersebut dirangkap dalam bentuk video berdurasi antara satu sampai lima menit. Tidak hanya majalah HighEnd yang memakai media sosial YouTube, namun kompetitor majalah HighEnd seperti majalah Prestige dan Dewi pun kerap menggunakan media sosial YouTube. Perbandingan viewers antara majalah HighEnd dan Prestige juga Dewi pun beragam, antara 50 viewers sampai 200 viewers. Namun jumlah viewers akan bertambah banyak jika majalah-majalah tersebut menampilkan video profile yaitu video yang berisikan tentang profil seseorang, dimana jumlahnya bisa mencapai 1000 viewers.

Berdasarkan uraian di atas, penelitian ini bertujuan untuk mengetahui bagaimana pemanfaatan media sosial YouTube sebagai sarana transformasi majalah HighEnd.

\section{KAJIAN PUSTAKA}

\subsection{Media Baru}

Media baru didefinisikan sebagai produk dari komunikasi yang termediasi teknologi yang 
terdapat bersamaan dengan komputer digital. Sebelum tahun 1980-an, media mengandalkan model cetak dan analog seperti surat kabar, televisi, bioskop dan radio. Sekarang kita memiliki radio digital, televisi digital, dan model cetak yang telah diubah oleh teknologi digital baru (Creeber \& Martin, 2009:2). Rasmussen (dalam McQuail, 2011:154) berpendapat bahwa media baru memiliki efek kualitatif berbeda terhadap integrasi sosial dalam jaringan masyarakat modern. Kontribusi pokoknya adalah untuk menjembatani jurang lebar yang terbuka antara dunia publik dan dunia privasi, antara dunia kehidupan, dan dunia sistem serta organisasi.

Pierre Levy dalam Littlejohn \& Foss (2009:413) memandang World Wide Web (WWW) sebagai sebuah lingkungan informasi yang terbuka, fleksibel dan dinamis, yang memungkinkan manusia mengembangkan orientasi pengetahuan yang baru dan juga terlibat dalam dunia demokratis tentang pembagian mutual dan pemberian kuasa yang lebih interaktif dan berdasarkan pada masyarakat. Dapat disimpulkan, bahwa media baru merupakan pembaruan penyebaran infromasi yang memanfaatkan teknologi, dan membuat suatu informasi menjadi lebih cepat tersebar serta lebih efesien dalam penyampaian suatu informasi.

Lister, Dovey, Giddings, Grant dan Kelly (2009:16-38) menyatakan terdapat enam karakteristik media baru, yaitu: 1) Digital, semua data diubah menjadi angka dalam proses media digital. Dalam hal ini media komunikasi dan representasi biasanya berbentuk grafik, gambar bergerak yang direkam, dan foto. Data yang telah diolah menjadi angka, kemudian diproses dan disimpan dalam bentuk sumber online, disk digital atau drive memori yang akan diterjemahkan dan diterima sebagai tampilan layar, dikirim lagi melalui telekomunikasi, jaringan atau output seperti hard copy. 2) Interaktifitas, merupakan salah satu karakteristik utama atau nilai dari media baru. Dimana media konvensional menawarkan konsumsi pasif, media baru menawarkan konsumsi secara lebih aktif. Media baru dapat dimiliki oleh semua orang dengan mudah dan hanya memerlukan jaringan internet. 3) Hypertextual, adalah memasukan kembali setiap informasi yang terdapat di media lama kedalam media baru dengan tampilan yang disesuaikan dengan tampilan media baru. Hal ini digunakan sebagai database infromasi yang terdapat di media baru tetap ada di media lama. 4) Jaringan; dapat diartikan bahwa di dalam media baru terdapat beberapa jaringan yang bertujuan untuk mempermudah konsumen memperluas partisipasi mereka. Jaringan tersebut antara lain World Wide Web (www), situs media sosial, situs web blog, forum online, situs web edukasi dan sebagainya. 5) Virtual, sifat maya dan mewujudkan dunia virtual yang diciptakan oleh keterlibatan grafik komputer dan video digital. Virtual juga berfungsi sebagai identitas postmodern, seni, hiburan, konsumen, dan budaya visual. 6) Simulasi, berarti menirukan beberapa dari media lama yang masih dapat digunakan di dalam media baru. Pengguna media baru juga dapat meniru infromasi apa yang mereka dapat di dalam media baru ke dunia nyata yang dimana hal tersebut dapat mempengaruhi hidupnya.

\subsection{Strategi Pemanfaatan Media Sosial Sebagai Sarana Transformasi}

Media sosial merupakan media online dimana para pengguna dapat mengakses segala informasi ataupun menyebarkan informasi melalui wadah tersebut. Menurut Safko (2010:5) media sosial adalah seperangkat alat baru, tekhnologi baru yang memungkinkan kita untuk lebih efisien terhubung dan membangun hubungan dengan pelanggan dan prospek kita.

Pertumbuhan pesat dari media sosial tidak dapat diabaikan begitu saja oleh praktisi industri media khususnya media cetak. Pola produksi dan distribu informasi telah mengalami pergeseran seiring penerapan perangkat komunikasi berbasis teknologi informasi dan komunikasi. Industri media cetak khususnya majalah mau tidak mau harus melakukan transformasi agar dapat bertahan dalam gempuran teknologi komunikasi saat ini. Menurut Goldhaber (1993) tranformasi merupakan perubahan yang dilakukan berdasarkan suatu saran atau masukan yang berujung berupa output perubahan. Dalam hal ini terdapat upaya mengubah atau membuat berbeda dari segi produksi hingga penyajian informasi yang dilakukan media saat ini.

Saat ini industri majalah tidak cukup dengan hanya memproduksi dalam bentuk cetak tetapi juga memproduksi informasi dan mengemasnya dalam bentuk media online, seperti YouTube, website dan sebagainya. Melalui media online ini pembaca diajak untuk berinteraksi dan tidak hanya melihat gambar yang monoton tetapi dalam bentuk video.

Terdapat empat strategi dalam pemanfaatan media sosial menurut Hootsuite (n.d., p.5) yaitu : 1) audience; target audience akan menentukan media sosial apakah yang cocok untuk digunakan. 2) 
mission; menetapkan misi dari media sosial yang akan digunakan, mengikat pada tujuan mengapa media sosial tersebut digunakan; 3) goal; yaitu menetapkan sasaran dari media sosial untuk mengindentifikasi tolak ukur kesuksesan. 4) strategy; langkah terakhir yang dilakukan yaitu mengembangkan strategi konten untuk media sosial tersebut.

\subsection{YouTube}

YouTube adalah salah satu media sosial yang berisikan berbagai macam video. YouTube didirikan pada bulan Februari 2005 oleh tiga orang yaitu Chad Harley, Steve Chen, dan Jawed Karim. Melihat prospek situs YouTube yang semakin baik, Google mengakuisisi situs ini pada bulan Oktober 2006 (Media, 2009:83). YouTube merupakan media sosial yang dapat digunakan secara gratis, maksudnya adalah, para pengguna dapat mengunggah video tanpa harus membayar, namun tetap membutuhkan internet atau paket data untuk dapat menikmati video-video yang ada di dalam YouTube. Para pengguna YouTube pun dapat memberikan komentar di kolom komentar yang tersedia di setiap video yang di posting pengguna lain. Selain dapat berkomentar, pengguna juga dapat memberikan like pada video pengguna lain apabila pengguna menyukai video tersebut.

YouTube mempunyai lima karakteristik (Faiqah, Nadjib, \& Amir, 2016:260): 1) Tidak ada batasan durasi untuk mengunggah video. Hal ini yang membedakan YouTube dengan beberapa aplikasi lain yang mempunyai batasan durasi minimal waktu semisal instagram, snapchat, dan sebagainya. 2) sistem pengamanan yang akurat, dimana YouTube membatasi pengamanannya dengan tidak mengizinkan video yang mengandung SARA, illegal, dan akan memberikan pertanyaan konfirmasi sebelum menggungah video. 3) Berbayar. Menurut Theoldman dalam Faiqah, Nadjib, \& Amir (2016:261) YouTube memberikan penawaran bagi siapapun yang mengunggah videonya dan mendapatkan minimal 1000 viewers penonton maka akan diberikan honorarium. 4) Sistem offline; YouTube memiliki fitur baru bagi para pengguna untuk menonton video secara sistem offline. Sistem ini memudahkan para pengguna untuk menonton video pada saat offline tapi sebelumnya video tersebut harus di download terlebih dahulu. 5) Tersedia editor sederhana. Pada menu awal menguggah video, pengguna akan ditawarkan untuk mengedit videonya terlebih dahulu. Menu yang ditawarkan adalah memotong video, memilah warna, atau menambahkan efek perpindahan video.

\section{METODE PENELITIAN}

Penelitian ini menggunakan metode penelitian deskriptif dengan pendekatan kualitatif. Metode penelitian deskriptif dengan pendekatan kualitatif ini digunakan dengan harapan dapat memperoleh informasi secara lebih mendalam dan akurat mengenai topik penelitian. Penelitian deskriptif bertujuan untuk mengumpulkan informasi lebih terperinci yang menggambarkan suatu fenomena.

Denzin dan Lincoln dalam Moleong (2010:5) menyatakan bahwa penelitian kualitatif adalah penelitian yang menggunakan latar alamiah, dengan maksud menafsirkan fenomena yang terjadi dan dilakukan dengan jalan melibatkan berbagai metode yang ada. Definisi tersebut menggambarkan bahwa penelitian kualitatif memiliki maksud dan tujuan untuk menafsirkan fenomena yang sedang terjadi.

Penelitian ini mewawancarai tiga narasumber yaitu Lysia Jessica selaku Editor in Chief majalah HighEnd; Larasati Oetomo selaku penanggung jawab akun YouTube HigEnd Magazine dan Johan Jang selaku pakar sosial media. Data yang diperoleh dianalisis menggunakan teknik analisis kualitatif model Miles and Huberman. Analisis data dilakukan secara interaktif yaitu berupa 1) reduksi data, dimana di tahap ini dilakukan proses reduksi segala informasi yang diperoleh untuk menfokuskan pada masalah tertentu; 2) penyajian data, dapat dilakukan dalam bentuk uraian singkat, bagan, ataupun teks yang bersifat naratif; dan 3) penarikan kesimpulan, diharapkan adanya temuan baru dapat berupa deskripsi atau gambaran suatu obyek (Sugiyono, 2010:431-438).

\section{HASIL DAN DISKUSI}

YouTube HighEnd Magazine adalah media sosial yang memberikan informasi seputar fashion lifestyle. Informasi tersebut dirangkap dalam bentuk video berdurasi antara satu sampai lima menit. YouTube HighEnd Magazine berisikan video-video mengenai bag check, fashion film, uncovers, juga quick Questions. YouTube HighEnd telah disubscribe sebanyak 445 per tanggal 1 Oktober 2017. 
Bertujuan untuk memperluas pembaca majalah HighEnd, kini HighEnd tidak bisa hanya terpaku pada media cetak saja. Perkembangan teknologi informasi dan komunikasi diikuti dengan perubahan gaya hidup masyarakatnya, tidak terkecuali di Indonesia; membuat industri media juga harus menyesuaikan diri agar bertahan hidup. Masyarakat Indonesia saat ini berada dalam fase transisi menuju masyarakat era informasi, yang membuat terjadi pergeseran pola atau cara masyarakat mengakses dan mendistribusikan informasi (Respati, 2014:49).

Perkembangan teknologi komunikasi ini, mau tidak mau membuat majalah HighEnd harus mengikuti perubahan. Majalah HighEnd melakukan sinergi dengan melakukan tranformasi pada distribusi pemberitaannya yaitu dengan menggunakan media sosial YouTube. Saat ini YouTube menjadi situs online video provider paling dominan di Amerika Serikat bahkan dunia, dengan menguasai $43 \%$ pasar. Jumlah jam yang diluangkan orang untuk menonton video di YouTube naik $60 \%$ pertahunnya dan merupakan pertumbuhan terpesat yang pernah dilihat dalam kurun waktu dua tahun terakhir (Faiqah, Nadjib dan Amir, 2016:260).

Dilihat dari karakteristik media baru, majalah HighEnd bertranformasi dari bentuk cetak ke dalam bentuk digital. Penyampaian informasi dalam bentuk cetak dengan digital tentunya berbeda. Demikian juga yang dilakukan oleh majalah HighEnd. Seperti yang disampaikan oleh digital media officer HighEnd, sebagai berikut: "kalo YouTube lebih banyak beda dengan majalah. Yang sama hanya pada konten HighEnd uncovers dan fashion film dan Event. Untuk Q\&A dan bag check ngga sesuai. Itu dibuat hanya bertujuan untuk memberikan informasi yang fun".

Hal tersebut di atas sesuai dengan Lister, Dovey, Giddings, Grant dan Kelly (2009:16) yang menyatakan bahwa salah satu karakteristik dari media baru yaitu digital dimana media komunikasi dan representasi biasanya berbentuk grafik, gambar bergerak yang direkam, dan foto. Data yang telah diolah menjadi angka, kemudian diproses dan disimpan dalam bentuk sumber online, disk digital atau drive memori yang akan diterjemahkan dan diterima sebegai tampilan layar, dikirim lagi melalui telekomunikasi, jaringan atau output seperti hard copy.

Orang-orang sudah mulai meninggalkan media cetak, dalam arti, orang lebih senang mencari suatu informasi melalui media sosial dibandingkan membaca secara fisik. Hal tersebut membuat media cetak seperti majalah tidak dapat lagi hanya terpaku pada satu media. Agar terus bertahan, media cetak perlu beradaptasi dengan perubahan zaman. Hal ini seperti yang disampaikan oleh pakar media sosial, sebagai berikut:

"Padangan saya mengenai majalah yang memanfaatkan media sosial seperti YouTube dan instagram, pandangan saya adalah media media ini sudah berada dijalur yang tepat. Karena mau tidak mau mereka harus beradaptasi dengan perubahan jaman. Perubahannya adalah tidak lagi, semakin sedikit lah, orang yang membaca majalah itu secara fisik".

Hal ini juga sesuai dengan pernyataan McQuail (2011:148) bahwa media baru merupakan perangkat teknologi komunikasi yang berbagi ciri yang sama dimana selain baru, dan memungkinkan juga digitalisasi dan ketersiadaannya yang luas untuk pengguna pribadi sebagai alat komunikasi.

Karakteristik media baru lainnya adalah interaktifitas. Salah satu fitur yang dimiliki YouTube yaitu fitur komentar, dimana pengguna YouTube dapat berinteraksi dengan cara berkomentar di dalam kolom komentar yang tersedia disetiap video. Transformasi yang dilakukan HighEnd dalam hal ini adalah adanya interaksi yang terjadi pada media sosial mereka yaitu YouTube. Berbeda pada media cetak, pembaca majalah HighEnd tidak dapat memberikan pendapat mereka secara langsung. Interaksi yang terjadi didalam YouTube HighEnd beraneka ragam, seperti memuji konten atau video, dan adapula yang memberikan inspirasi positif dalam kolom komentar. Sesuai dengan pernyataan Lister, Dovey, Giddings, Grant dan Kelly (2009:21) bahwa interaktivitas telah menjadi salah satu karakteristik utama atau nilai dari media baru. Dimana media konvensional menawarkan konsumsi pasif, media baru menawarkan konsumsi secara lebih aktif. Media baru dapat dimiliki oleh semua orang dengan mudah dan hanya memerlukan jaringan internet.

Hypertextual juga terdapat dalam media baru. Beberapa video yang diunggah oleh HighEnd ke dalam YouTube merupakan informasi yang terdapat di dalam media cetak. Informasi di media cetak di adaptasi dengan tampilan yang disesusaikan. Transformasi yang dilakukan oleh HighEnd dalam hal ini adalah memasukan kembali beberapa informasi yang terdapat pada majalah ke dalam akun YouTube, dengan konsep yang berbeda, dengan tampilan yang disesuaikan. Hal ini seperti yang disampaikan oleh digital media officer HighEnd sebagai berikut: "Sebenernya namanya ga sama, 
cuman intinya sama. Kayak HighEnd uncovers di YouTube itu sebenernya sama kayak artikel people profile di majalahnya".

Lister, Dovey, Giddings, Grant dan Kelly (2009:26) yang menyatakan bahwa hypertextual adalah memasukan kembali setiap informasi yang terdapat di media lama ke dalam media baru dengan tampilan yang disesuaikan dengan tampilan media baru. Hal ini digunakan sebagai database informasi yang terdapat di media baru tetap ada di media lama. Sebagian industri melihat bahwa media sosial hanyalah sebagai wadah perpindahan, tanpa memikirkan isi atau konten. Padahal hal yang penting dalam memasukan kembali suatu informasi kedalam media sosial adalah melakukan perubahan konten.

Karakteristik media baru lainnya adalah adanya jaringan. Dengan adanya jaringan, pengguna teknologi komunikasi khususnya media sosial mendapatkan kemudahan. YouTube HighEnd terhubung dengan media sosial lainnya, sehingga seseorang dapat dengan mudah mengakses ke media sosial HighEnd lainnya. Selain itu media baru juga memunculkan ciri virtual, yaitu bagaimana media massa menyampaikan suatu informasi dalam bentuk nyata ke media digital dengan melibatkan grafik komputer dan video digital. YouTube HighEnd menggunakan effects, dan color tersendiri untuk membedakan dari kompetitor lainnya.

Tranformasi yang dilakukan oleh HighEnd dalam hal ini adalah adanya perbedaan visual yang terjadi pada akun YouTube. Apabila pada media cetak gambar dan tulisan terlihat monoton, HighEnd mengadaptasi hal tersebut pada YouTube. Pada YouTube pembaca dapat menikmati suatu informasi dengan gambar yang bergerak serta pewarnaan yang dibuat sedikit berbeda oleh HighEnd. Pada YouTube HighEnd membuat video mereka memiliki saturasi warna yang rendah, yang tidak terlalu kontras. Sesuai dengan Lister, Dovey, Giddings, Grant dan Kelly (2009:36) Karakteristik ini memiliki sifat yang maya dan mewujudkan dunia virtual yang diciptakan oleh keterlibatan grafik komputer dan video digital.

Video tanpa pewarnaan atau effect hanya akan bertahan sekitar lima menit. Hal tersebut dikarenakan orang akan lebih senang jika suatu video memiliki warna atau effect atau suara. Hal tersebut memiliki peran penting dalam industri media, hal ini seperti yang disampaikan oleh pakar media sosial, sebagai berikut:

"Video yang tanpa effect sama sekali itu mungkin kita bisa hanya bisa bertahan sekitar 5 sampai 7 menit tapi setelah itu udah, udah langsung bosen dan di tutup nah ganti dengan video berikutnya. Jadi warna effect kemudian mungkin animation-animation lah ya segala macem itu dapat menyebabkan konten itu bisa menyebabkan lebih lama. Konten yang bisa melebihi 10 menit atau bahkan 15 menit gitu. Nah konten-konten yang sangat entertainment ini yang memang mau ngga mau kalau kita bicara di industri media, mereka lebih bermain di audio visual jadinya gitu. Bermain di warna, bermain di effect, bermain di musik gitu ya. Supaya video mereka bisa lebih lama di tonton dan lebih mau di tonton oleh orang-orang gitu."

Video yang di unggah HighEnd ke dalam YouTube sudah merupakan simulasi dari penggabungan digital dengan virtual yang menciptakan suatu infromasi berupa gambar bergerak atau video. Transformasi yang dilakukan oleh HighEnd dalam hal ini adalah adanya penggabungan digital dan virtual sehingga terciptanya suatu karya berupa video. YouTube sebagai bentuk digital untuk menyampaikan konten spesial yang dimiliki majalah HighEnd seperti cover majalah dan profile. Hal tersebut seperti yang disampaikan oleh digital media officer HighEnd, sebagai berikut:

"Kalau untuk konten majalah plus YouTube itu biasanya memang untuk sepesial konten kayak cover atau misalnya ditengah-tengah tuh suka ada kertas yang beda sendiri itu kan, yang special coverage nya. Itu kadang-kadang disitu juga ada. Cuman yang hampir pasti itu cover, kecuali covernya artis luar. sama special profile".

Transformasi dalam pendistribusian informasi melalui YouTube tidak mungkin dapat berjalan maksimal apabila tidak ada strategi dalam memanfaatkan media tersebut. Menurut Hootsuite (n.d.:5) terdapat 4 strategi awal dalam memanfaatkan media sosial, yaitu; menetapkan audience yang dituju, menetapkan misi dari media sosial tersebut, menetapkan sasaran dari media sosial untuk mengindentifikasi tolak ukur kesuksesan, serta mengembangkan strategi konten untuk media sosial tersebut. 


\section{Audience}

Langkah pertama yang dilakukan majalah HighEnd yaitu menetapkan audience yang dituju guna mengetahui media sosial apa yang pantas untuk digunakan. YouTube HighEnd memiliki target audience antara usia belasan hingga usia 30 tahun. Mereka menargetkan usia yang cukup produktif dan terbilang lebih muda dibandingkan target pembaca pada majalah. hal ini seperti yang disampaikan oleh digital media officer HighEnd sebagai berikut:

"Untuk YouTube kan memang sebenarnya lebih mengarah ke yang muda. Antara millennial sampai dengan generasi $\mathrm{Z}$. Dari belasan yang masih sekolah sampai thirty lah ya 30 an orang masih buka YouTube. Cuman kayaknya kalo untuk segment utamanya HighEnd majalah sebenernya ga terlalu, Karena biasanya kan 40an yang udah ibu-ibu lah ya. Cuman ini lebih nargetin yang lebih mudanya gitu".

Berbeda dengan target pembaca untuk majalah cetak yang memiliki karakteristik usia lebih tua yakni 35 sampai 45 tahun, pada YouTube ditetapkan usia yang lebih muda dikarenakan untuk menyasar pembaca muda. Setelah target pembaca terbentuk, HighEnd mencari tahu media sosial apakah yang cocok untuk digunakan. Melihat usia yang dituju adalah usia yang berasal dari generasi Millenial hingga generasi Z. Dimana menurut penelitian Benesik, Csikos dan Juhez dalam Putra (2016:130) generasi Millenial adalah generasi yang lahir antara tahun 1980-1995 dan generasi Z yaitu yang lahir antara tahun 1995-2010. HighEnd membutuhkan media sosial yang mampu memberikan informasi berupa audio dan visual, maka HighEnd menggunakan media sosial YouTube sebagai sarana transformasi media cetak mereka. Disamping itu, YouTube memiliki durasi yang lebih panjang dibandingkan instagram dan media sosial lainnya juga lebih mudah untuk diakses.

\subsection{Misi}

Strategi kedua yang dilakukan HighEnd adalah menetapkan misi dari media sosial yang digunakan yaitu YouTube. HighEnd mengharapkan dengan adanya YouTube, orang akan lebih mengenal majalah HighEnd, dan menumbuhkan rasa keingin tahuan mereka terhadap HighEnd. Hal ini seperti yang disampaikan oleh digital media officer HighEnd, sebagai berikut:

"hmm ada beberapa sih.. yang satu tuh untuk ngenalin orang seenggaknya untuk awareness ke HighEnd nya gitu. Jadi orang mungkin gak langsung beli, tapi dari sebelum dia beli udah tau gitu kan, mungkin "oh gue pernah liat di YouTube" "oh gue pernah liat di instagram temen gue pernah ngelike" atau semacamnya. Jadi ketika dia ngeliat majalahnya oh mungkin lebih tertarik gitukan. Jadi kayak medium promosi gitu kan untuk majalahnya" .

HighEnd menginginkan konten yang terdapat didalam YouTube memiliki informasi yang lebih fresh, light, dan lebih consumable untuk dinikmati sehari-hari. Berbeda dengan informasi yang terdapat dimajalah, karena majalah HighEnd hanya terbit sekali dalam sebulan. Hal ini seperti yang ditambahkan oleh digital media officer HighEnd, sebagai berikut:

"Yang kedua kita memang ingin bikin konten original yang lebih update it. Karna kalau majalah kan bulanan, kalo ini kan semua harian gitu, website, YouTube, instagram semua harian. Jadi kita pengen ngejar yang lebih, orang bisa langsung googling nyari gitu kan, langsung ketemu gitu berita-berita terbaru sama juga kenapa butuh konten baru karna kita pengen geser ke konten yang ngga semua konten yang di majalah itu fit to the digital gitu kan. Mungkin untuk fashion spread orang akan lebih seneng liat print langsung dibanding di media. Karena di media memang traffic nya ga terlalu tinggi. Jadi kita memang bener-bener pengen bikin konten yang lebih fresh, lebih light, lebih consumable buat sehari-sehari dibanding majalah gitu yang cenderung lebih berat".

Berdasarkan kedua pernyataan tersebut terlihat misi terbentuknya YouTube HighEnd adalah sebagai medium untuk lebih mengenalkan majalah HighEnd kepada khayalak luas melalui media sosial YouTube agar mereka tertarik untuk membaca majalah HighEnd. Selain itu HighEnd ingin menampilkan informasi yang lebih terkini, fresh, yang dapat dinikmati sehari-hari dibandingkan yang 
ada di majalah, dikarenakan majalah HighEnd adalah majalah bulanan, sehingga pembaca akan lebih mudah mendapatkan informasi dari HighEnd.

\subsection{Goal}

Strategi ketiga yang dilakukan HighEnd adalah menetapkan sasaran dari media sosial untuk mengindentifikasi tolak ukur kesuksesan. Jumlah views dan likes dalam YouTube HighEnd menjadikan salah satu tolak ukur kesuksesan. HighEnd memiliki subscriber pada YouTube yang terus meningkat. Namun untuk viewers dan likes dari setiap video amatlah beragam, hal tersebut dikarenakan orang akan lebih senang melihat konten yang fun dibandingkan konten yang monoton. Seperti yang disampaikan oleh digital media officer HighEnd, sebagai berikut:

"Untuk subscriber itu naik, tapi kalau untuk apakah semuanya naik tuh ngga juga. Ada beberapa yang naik, ada beberapa yang engga. Jadi karna untuk konten-konten baru lebih naik di trafficnya kalau kita pasangnya untuk orang-orang yang istilahnya punya based fansnya gede, kayak misalnya si miss Indonesia, Cinta Laura juga, biasanya masih local sih kalau untuk luar gitu engga terlalu tinggi cuman lebih banyak profile untuk naiknya atau quick questions yang lebih fun gitukan. Tapi kayaknya kalau untuk fashion film, video event, event coverage itu ga terlalu naik sebenernya".

Selain itu, HighEnd mengharapkan dengan adanya YouTube dapat memperluas konten dan juga dapat menyebarkan informasi yang lebih luas agar dampaknya lebih terasa. Hal tersebut seperti yang ditambahkan oleh editor in chief HighEnd, sebagai berikut: "extending \& expending our content. Tidak Cuma di print tapi dalam dunia digital sehingga bisa menyebarkan news lebih luas agar dampaknya lebih terasa".

Melihat hal tersebut menjadikan HighEnd mengerti bahwa terdapat hal-hal tertentu yang harus di perhitungkan sebelum membuat sebuah konten untuk YouTube HighEnd. Dari jawaban Larasati terlihat bahwa video yang terdapat di YouTube HighEnd akan lebih banyak mendapatkan viewers dan likes apabila artis yang terdapat dalam video tersebut memiliki penggemar yang banyak. Dan nantinya beberapa dari mereka akan merasa ingin tahu lebih dalam mengenai HighEnd, yang akhirnya akan melihat video lain di akun YouTube HighEnd selain idolanya.

\subsection{Strategi Konten}

Langkah terakhir yang dilakukan HighEnd yaitu mengembangkan strategi konten untuk media sosial tersebut. Strategi tersebut berupa pemilihan konten, pemilihan warna, effect, serta jadwal penanyangan video di akun YouTube. Konten yang ada pada YouTube HighEnd memang sedikit berbeda dengan yang ada di majalah cetak. Hal ini dikarenakan tidak semua konten di dalam majalah cetak dapat masuk ke dalam versi YouTube. Hal ini seperti yang disampaikan oleh media officer HighEnd, sebagai berikut:

"Oh iya memang kan kadang-kadang sekali jalan ya. Kalau untuk konten majalah plus YouTube itu biasanya memang untuk sepesial konten kayak cover atau misalnya ditengahtengah tuh suka ada kertas yang beda sendiri itu kan, yang special coverage nya. Itu kadangkadang disitu juga ada. Cuman yang hampir pasti itu cover, kecuali covernya artis luar. sama special profile".

Artinya, HighEnd lebih memilih konten yang informatif namun fun. Akan tetapi beberapa hal yang terdapat di dalam majalah masih akan tetap ada di akun YouTube HighEnd seperti video tentang uncovers atau fashion film dan event. Seperti yang disampaikan oleh digital media officer HighEnd, sebagai berikut:

"Kalo YouTube lebih banyak beda dengan majalah. Yang sama hanya pada konten HighEnd uncovers dan fashion film dan Event. Untuk Q\&A dan bag check ngga sesuai. Itu dibuat hanya bertujuan untuk memberikan informasi yang fun".

Selain konten yang telah ditentukan, HighEnd juga memiliki ciri khas tersediri pada warna dan effect dari setiap video mereka. Seperti yang Larasati katakan, video di dalam YouTube HighEnd memiliki warna sendu. Yaitu pewarnaan yang rendah, yang tidak terlalu kontras, seperti warna abu-abu atau biru sendu. Hal ini bertujuan untuk membedakan HighEnd dari kompetitor lainnya. Hal ini seperti 
yang disampaikan oleh digital media officer HighEnd, sebagai berikut: "iya, kalo HighEnd pasti sendu gitu. Yang biru warna, low saturation, yang ga terlalu contras, abu-abu atau biru”.

Berkaitan dengan jangka waktu penanyangan video, ditemukan bahwa antara satu video dengan video lain yaitu seminggu sekali dengan durasi setiap video dalam YouTube HighEnd berkisar antara satu hingga lima menit. Hal tersebut sesuai dengan pernyataan dari digital media officer HighEnd, yang menyatakan bahwa: "seminggu sekali video sudah harus ada di YouTube HighEnd". Larasati Oetomo juga menambahkan, bahwa yang paling lama biasanya untuk quick questions, tergantung pertanyaannya. Durasinya bisa tiga sampai empat menit.

Dari pernyataan di atas maka dikatakan bahwa penetapan target pembaca, misi dari penggunaan YouTube sebagai media transformasi majalah HighEnd serta sasaran dan strategi konten sangat diperlukan agar dapat bersaing dan bertahan dalam era teknologi komunikasi dan informasi saat ini.

\section{SIMPULAN}

YouTube HighEnd Magazine merupakan salah satu media sosial yang digunakan majalah HighEnd sebagai sarana transformasi dari bentuk media cetak menjadi media digital, yang menyasar pembaca baru di usia belasan sampai 30 tahun, berbeda dengan target pembaca untuk majalah cetaknya yang menyasar pembaca di usia 35-45 tahun. YouTube dianggap mampu memberikan informasi berupa audio dan visual dan memberi kemudahan untuk diakses. Konten majalah HighEnd di YouTube mengarah kepada konten informasi yang fresh, light dan lebih consumable, yang dapat diakses setiap saat, yang berbeda dengan majalah cetaknya, yang terbit sekali dalam sebulan.

Dalam bentuk digital majalah HighEnd memasukan kembali informasi yang terdapat di dalam majalah cetak ke dalam media sosial YouTube yakni berupa video atau gambar bergerak. Walaupun tidak sepenuhnya apa yang terdapat di majalah cetak di masukkan ke dalam aku HighEnd Magazine. YouTube HighEnd telah memanfaatkan jaringan yang ada untuk memperluas partisipasi mereka, dimana HighEnd memberikan kemudahan dalam mengakses segala media sosial untuk mendapatkan infromasi. Penggunaan warna yang sendu, yaitu warna abu- abu atau biru yang memiliki saturasi rendah pada setiap video mereka, sebagai ciri khas dari HighEnd untuk membedakan dengan majalah lainnya.

Sinergi yang dilakukan dengan melakukan transformasi pada distribusi pemberitaannya ini, tentunya dapat membuat majalah HighEnd terus bertahan dan merangkul konsumen yang aktif dalam mengkonsumsi media khususnya majalah. Dimana dengan menggunakan jaringan media baru yaitu YouTube pembaca dapat dengan mudah mengakses informasi yang dibutuhkannya.

\section{DAFTAR PUSTAKA}

Creeber, G. \& Martin, R. (2009). Digital Cultures: Understanding New Media. Berkshire-England: Open Univerity Press.

Faiqah, F., Nadjib, M., \& Amir. A. S. (2016). Kareba. YouTube Sebagai Sarana Komunikasi Bagi Komunitas Makassarvidgram, 5(2), 259-272. Diakses melalui E-Journal: http://journal.unhas.ac.id/index.php/kareba/article/view/1905/1063

HighEnd. (2017). HighEnd Magazine Media Kit 2017. Jakarta: HighEnd.

Hootsuite. (n.d.). The All-in-One Socia Media Strategy Workbook. Canada: Hootsuite.

Lister, M., Dovey, J., Giddings, S., Grant, I., \& Kelly, K. (2009). New Media - A Critical Introduction Second Edition. New York: Routledge.

Littlejohn, S. W. \& Foss, K. A. (2009). Teori Komunikasi. Jakarta: Salemba Humanika.

Maheswara, J. \& Dwiutami, L. (2013). JPPP. Pola Perilaku Dewasa Muda Yang Kecenderungan Kecanduan Situs Jejaring Sosial, 2(1), 51-62. Diakses melalui E-Journal: http://journal.unj.ac.id/unj/index.php/jppp/article/download/4363/3279/

McQuail, D. (2011). Teori Komunikasi Massa Mcquail Edisi 6. Jakarta: Salemba Humanika.

Media, L. (2009). YouTube \& Google Video; Membuat, Mengedit dan Upload Video. Yogyakarta: MediaKom.

Moleong, L. J. (2010). Metodologi Penelitian Kualitatif Edisi revisi. Bandung: PT Remaja Rosdakarya.

Mukhtar. (2013). Metode Praktis Penelitian Deskriptif Kualitatif. Jakarta: Referensi (Gaung Persada Press Group). 
Press@google.com. (n.d.). YouTube Untuk Pers. Diperoleh dari website: https://www.YouTube.com/intl/id/yt/about/press/

Putra, Y. S. (2016). Among Makarti. Theoritical Review: Teori Perbedaan Generasi. 9(18), 123 134. Diakses melalui E-Journal: http://jurnal.stieama.ac.id/index.php/ama/ article/viewFile/142/133

Respati, W. (2014). Humaniora. Transformasi Media Massa Menuju Era Masyarakat Informasi Di Indonesia, 5(1), 39-51. Diakses melalui E- Journal: https://media.neliti.com/media/publications/167082-ID- transformasi-media-massa-menujuera-masy.pdf

Safko, L. (2010). The Social Media Bible Second Edition. New Jersey: John Wiley \& Sons, Inc.

Slideshare.net. (2017).Digital in 2017: Southeast Asia. Diperoleh dari website SlideShare: https://www.slideshare.net/wearesocialsg/digital-in-2017- southeast-asia

Sugiyono. (2010). Memahami Penelitian Kualitatif. Bandung: Alfabeta, cv.

Yusuf, A. M. (2014). Metode Penelitian: Kuantitatif, Kualitatif dan Penelitian Gabungan Edisi Pertama. Jakarta: Prenadamedia Group. 